\title{
The Future Direction of Radiopharmaceutical Development
}

\author{
Philip J. Blower
}

The first use in humans of ${ }^{24} \mathrm{Na}$-sodium chloride by Hamilton and Stone in 1936 [1] began a story in which ${ }^{131}$ I-iodide became established for treating thyroid disease and radionuclide imaging became routine in hospitals. As important as the first commercial gamma camera (1968) [2] was the ${ }^{99 \mathrm{~m}}$ Tc generator, an elegantly simple device that solved the problem of world-wide distribution of a short half-life radionuclide, first used for medical purposes in 1961 [2]. A range of ${ }^{99 \mathrm{~m}} \mathrm{Tc}$-radiotracers quickly became available, including complexes of DTPA (renal function, lung ventilation), meso-DMSA (renal perfusion), bisphosphonates (bone), HIDA (liver) and various colloids (predating "nanotechnology" by decades) and macroaggregated albumin. They were easily synthesised in hospitals using simple kit vials, firmly establishing ${ }^{99 \mathrm{~m}} \mathrm{Tc}$ as the staple medical radionuclide. They were largely serendipitous, arising from biological experiments using "off the shelf" chelating ligands selected without detailed knowledge of basic technetium chemistry [3], which was almost unstudied at that time. The simple preparation disguised extremely complex coordination chemistry. In most cases their structures remain unknown even now, and their approval in today's regulatory climate would have been most unlikely. Nevertheless they were extremely successful.

In the 1980s and 1990s, pioneered by leaders such as Davison and Deutsch, understanding of technetium chemistry grew [4] producing a new generation of tracers with a greater element of chemical design and with well-defined structures, but still with simple, kit-based labelling. The concept of technetium "cores" emerged - well-defined, stable complexes adapted to the coordination preferences of technetium, that could be functionalised for different purposes. Examples include the $\mathrm{TcO}^{3+}$ core (the basis of tracers such as MAG3 complex for renal function

P.J. Blower

Division of Imaging Sciences and Biomedical Engineering,

King's College London, St Thomas' Hospital, 4th Floor Lambeth Wing,

London SE1 7EH, UK 
imaging, "pentavalent" DMSA complex for medullary thyroid carcinoma and bone disease, HMPAO complex for cerebral perfusion imaging and cell labelling), $\mathrm{Tc}$ (isonitrile) ${ }_{6}^{+}$(sestamibi for myocardial perfusion imaging), $\mathrm{TcO}_{2}{ }^{+}$(with tetraamine or diphosphine chelating ligands such as tetrofosmin), $\operatorname{Tc}(\mathrm{CO})_{3}{ }^{+}$and $\mathrm{TcN}(\text { dithiocarbamate })_{2}$.

This set the stage for radiotracer design to shift towards targeting specific receptors and transporters, by incorporating ${ }^{99 \mathrm{~m}} \mathrm{Tc}$ into peptides and proteins [3], and the term "molecular imaging" became both fashionable and relevant. It remained an important aspiration to synthesise ${ }^{99 \mathrm{~m}} \mathrm{Tc}$-radiopharmaceuticals via simple processes that are quick and use mild, aqueous conditions, avoiding the need for purification which adds undesirable complexity. However, ${ }^{99 \mathrm{~m}} \mathrm{Tc}$ chemistry is complex, entailing both exchange of ligands and reduction of Tc(VII), and success has been limited. Radiolabelling procedures for biomolecules still involve multiple manipulations and poor specific activity. Hydrazinonicotinamide (hynic) and tricarbonyl $\left(\mathrm{Tc}(\mathrm{CO})_{3}{ }^{+}\right)$complexes come closest to achieving this, but both fall short and neither has led to commercial products. Due to a shift in commercial interests towards PET, very little effort has been devoted to this problem in the last decade and it remains a challenge to achieve "one-step" ${ }^{99 \mathrm{~m}} \mathrm{Tc}$ biomolecule labelling.

Although emergence of positron emission tomography (PET) was roughly contemporaneous with that of the gamma camera, PET only became a routine clinical diagnostic tool in the 1990s, primarily driven by clinical use of the glucose analogue ${ }^{18}$ F-fluorodeoxyglucose. The clinical adoption of PET demanded significant investment in infrastructure, requiring cyclotron installation within $2-4 \mathrm{~h}$ travelling distance of PET scanners. Availability of this costly new infrastructure spawned development of a much wider variety of PET tracers to enhance its versatility. Its better resolution and quantification made it increasingly attractive even for applications that do not require organic small molecules, creating roles for metallic positron-emitting radionuclides $-{ }^{68} \mathrm{Ga},{ }^{89} \mathrm{Zr}$ and copper isotopes ${ }^{60 / 61 / 62 / 64} \mathrm{Cu}$ - which, like ${ }^{99 \mathrm{~m}} \mathrm{Tc}$, are easier to use for proteins and peptides than ${ }^{18} \mathrm{~F}$ and ${ }^{11} \mathrm{C}$.

${ }^{68} \mathrm{Ga}$ (half-life $68 \mathrm{~min}$ ) is rapidly emerging as "the new technetium" - a short half-life, generator-produced radiometal that is easily introduced into biomolecules. It produces a high positron yield and is readily chelated [5] with good kinetic stability. Despite growing clinical use, especially in Europe, the first commercial generator received marketing authorisation as recently as 2014. Although gallium chemistry is simpler than that of technetium (with only one relevant oxidation state (III)), the established chelating agents used to couple it to biomolecules require heating, low $\mathrm{pH}$ and purification steps, and have not been conducive to use in hospitals with limited radiochemistry facilities. A single-step, kit-based labelling procedure that works at room temperature, moderate $\mathrm{pH}$ and very low concentration would greatly increase its utility. Fortunately, considerable efforts have focused recently on developing new chelators to overcome these problems [5] and we will see their impact soon (Fig. 19.1).

Large biomolecules (e.g., monoclonal antibodies) with slow localisation and clearance require longer half-life tracers. The staple long half-life gamma-emitter has been ${ }^{111}$ In, which can be attached to proteins using bifunctional chelators, usually DTPA and DOTA. A longer half-life "PET analogue" has inevitably emerged: 


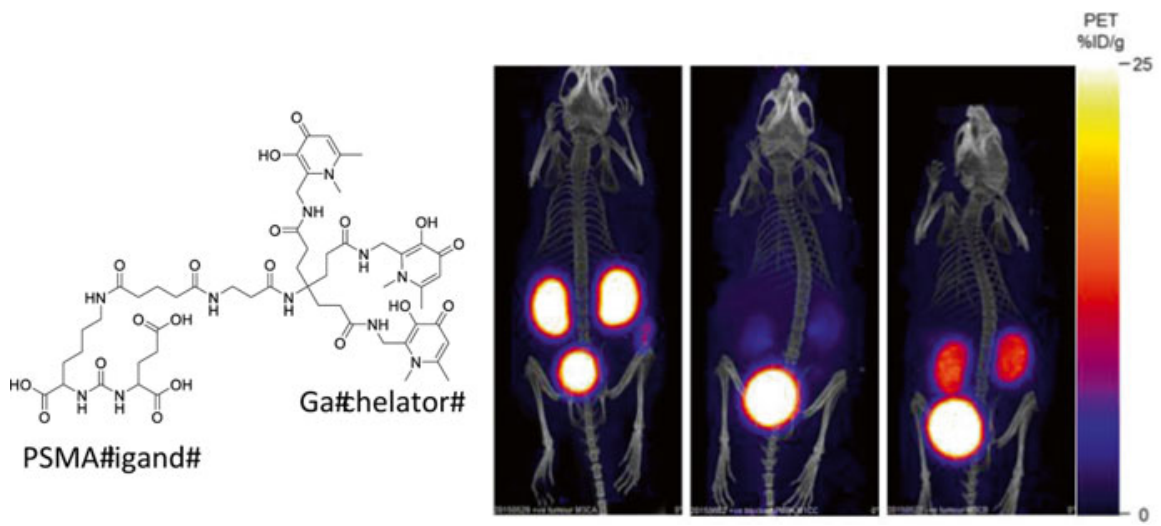

Fig. 19.1 PET-CT images of mouse bearing prostate-specific membrane antigen (PSMA) expressing prostate tumour (left), PSMA-expressing tumour (previously injected with a blocking dose of PSMA ligand) (centre), and PSMA-negative tumour (right), $1 \mathrm{~h}$ after injection of ${ }^{68} \mathrm{Ga}$-labelled PSMA ligand conjugate of a tris(hydroxypyridinone) chelator (left) synthesised by a kit method at room temperature and $\mathrm{pH} 7$ (Young J, Mullen GED, Blower PJ, 2015)

zirconium-89, and with desferrioxamine B as an effective bifunctional chelator for zirconium, ${ }^{89} \mathrm{Zr}$ PET has now been used to image the biodistribution and targeting of many antibodies ("immunoPET") in animal models and humans [6]. Longer-lived radionuclides can also usefully be incorporated into living cells to image their migration in vivo. Tracking leukocytes in this way using ${ }^{111} \mathrm{In}$ or ${ }^{99 \mathrm{~m}} \mathrm{Tc}$ has been routine since the 1980s. A PET analogue would offer improvements in sensitivity, quantification and resolution suitable for new challenges in cell tracking emerging from the development of cell-based therapies and discoveries in cellular immunology. Indeed, the first ${ }^{89} \mathrm{Zr}$ cell labelling radiopharmaceuticals have been reported recently [7] (Fig. 19.2). Refinement in their chemistry, widespread preclinical and clinical application, and commercial availability may be anticipated in the coming years.

While ${ }^{64} \mathrm{Cu}$ has been widely studied in the last 20 years as a medium half-life positron emitter for biomolecule labeling, cell tracking and hypoxia imaging, it has begun to give way to alternatives. However its potential to study pathophysiological changes in copper trafficking (Fig. 19.3) in, for example, Wilson's disease, Menkes' disease, dementias (notably Alzheimer's), cancers and nutritional abnormalities [8] is now emerging. Similar possibilities are emerging to study other essential trace metals such as zinc (using ${ }^{63} \mathrm{Zn}$ ) and manganese (using ${ }^{52} \mathrm{Mn}$ ). This is a new field in which molecular imaging with radionuclides can make a major impact.

The combination of different imaging modalities that complement each other to overcome their individual limitations is a current trend. For example, while PET and SPECT have exquisite sensitivity (sub-picomolar concentrations in vivo) and provide truly "molecular" imaging, their resolution is poor. Magnetic resonance imaging (MRI), on the other hand, offers better anatomical resolution but large amounts of contrast agent are required, while optical imaging can be used at cell level [9] (unlike radionuclides and MRI) but is restricted in clinical use by poor tissue penetration. A new generation of scanners combining PET and MRI is now entering 

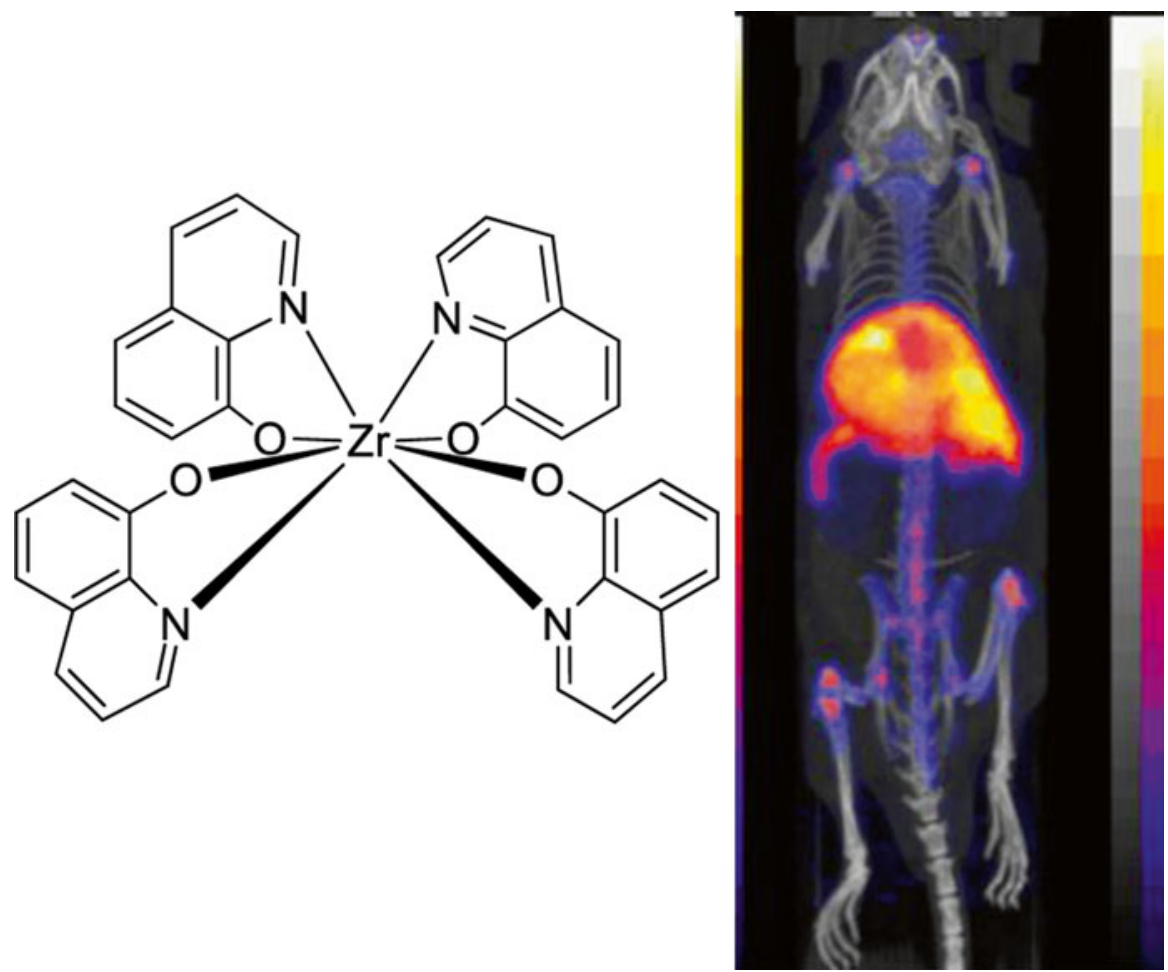

Fig. 19.2 Cell tracking with PET. PET-CT image of mouse 7 days after intravenous injection of 5T-33 myeloma cells labelled with ${ }^{89} \mathrm{Zr}$ tetrakis(oxinate), showing trafficking to liver, spleen and bone marrow (Ref. [7])

clinical use, driving new chemistry to produce combined modality contrast agents. For example, incorporating radionuclides into superparamagnetic iron oxide nanoparticles (SPION) allows combination of PET or SPECT with MRI. While particulate radiopharmaceuticals have been clinically used since the earliest days of nuclear medicine, the recent accumulation of capability in design, synthesis and characterisation of nanoparticles greatly enhances potential for multimodality imaging, albeit in specific niche areas such as imaging sentinel lymph nodes [10] (Fig. 19.4), reticuloendothelial system (liver, spleen, bone marrow), tumours (exploiting the enhanced permeability and retention effect), cell labelling and liposome-mediated drug and gene delivery.

In summary, the close cooperation of clinicians, physicists, engineers, biologists and chemists identifies capabilities, conceives challenges, discovers solutions and applies them in the clinic. Each discipline produces innovations that in turn drive innovations in the others. This is illustrated by the shift in the last decades from single photon radionuclide imaging towards PET, and in turn the 
Fig. 19.3 PET-CT imaging of copper trafficking. Sagittal section (anterior at top of image) of mouse brain $30 \mathrm{~min}$ after injection of $64 \mathrm{Cu}$-acetate, showing delivery to brain via choroid plexus. Left ventricle and fourth ventricle are indicated by arrows (Andreozzi, Bagunya-Torres, Blower, 2015)

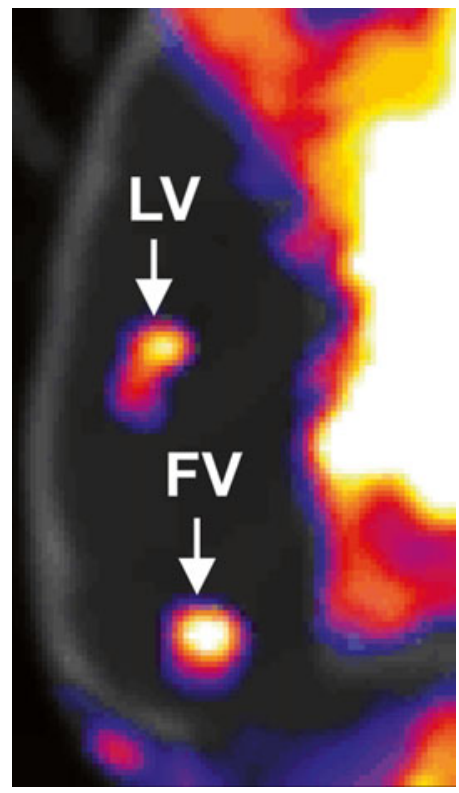

emerging shift from PET/CT towards PET/MRI and combination of these with optical imaging [9], which has led to new PET and combined modality radiopharmaceuticals. The next decade may see this recapitulated: the development of a new generation of gamma/SPECT scanners with resolution rivalling or exceeding that of PET will encourage renewed use and development of ${ }^{99 \mathrm{~m}} \mathrm{Tc}$ tracers. The recently highlighted global fragility of ${ }^{99 \mathrm{~m}} \mathrm{Tc}$ supply, far from foreshadowing the demise of ${ }^{99 \mathrm{~m}} \mathrm{Tc}$ and SPECT, has stimulated renewed international effort to plan new reactors and cyclotron-based production, and develop new generator designs to cope with lower specific activity ${ }^{99} \mathrm{Mo}$. This may soon stimulate a reversal in the recent decline of ${ }^{99 \mathrm{~m}} \mathrm{Tc}$ chemistry research, producing innovations appropriate to the age of molecular imaging. New initiatives to develop a whole body PET scanner will stimulate increased use of short half-life radionuclides in combination (e.g., ${ }^{82} \mathrm{Rb},{ }^{62} \mathrm{Cu},{ }^{13} \mathrm{~N},{ }^{18} \mathrm{O}$ ) in a research setting, for metabolic characterisation of tissues in unprecedented detail by imaging multiple molecular targets in a single subject, again potentially in combination with MRI and MR spectroscopy. The arrival of cell-based therapies will bring improvements in use of radiopharmaceuticals for cell tracking, again using a multimodality approach. Conversely, the arrival of new, simple chemistry for ${ }^{68} \mathrm{Ga}$ may drive the installation of more PET scanners.

On a final optimistic note, there are hopeful signs that the adverse regulatory climate in the new millennium, which has held back the clinical and commercial translation of the wealth of new molecular imaging chemistry developed in the last 15 years, is at last becoming more amenable. 


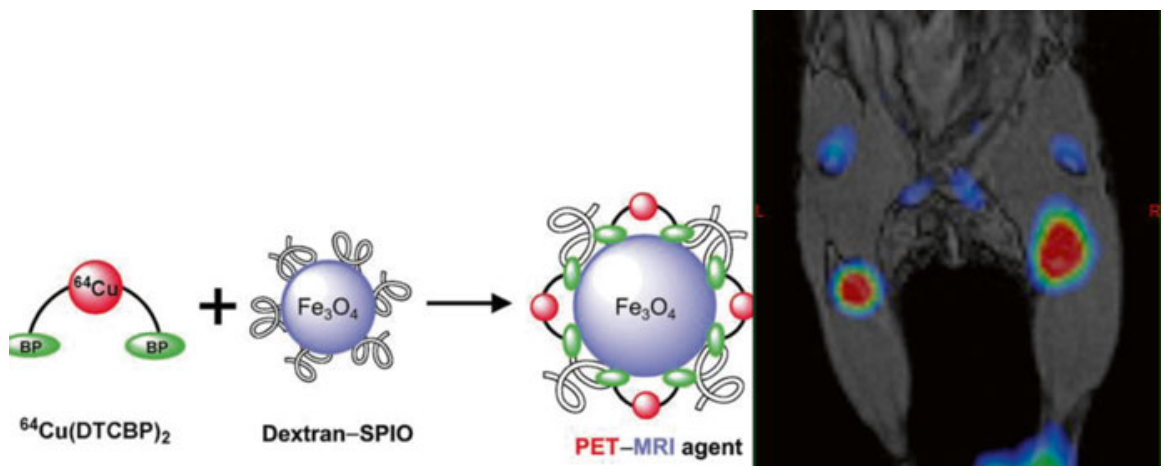

Fig. 19.4 Coronal PET-MRI image of mouse (right) after bilateral foot pad injection of ${ }^{64} \mathrm{Cu}$-labelled iron oxide particles (left), showing transport to popliteal and iliac lymph nodes (Ref. [10])

Open Access This chapter is distributed under the terms of the Creative Commons AttributionNoncommercial 2.5 License (http://creativecommons.org/licenses/by-nc/2.5/) which permits any noncommercial use, distribution, and reproduction in any medium, provided the original author(s) and source are credited.

The images or other third party material in this chapter are included in the work's Creative Commons license, unless indicated otherwise in the credit line; if such material is not included in the work's Creative Commons license and the respective action is not permitted by statutory regulation, users will need to obtain permission from the license holder to duplicate, adapt or reproduce the material.

\section{References}

1. Heilbron JL, Seidel RW. Lawrence and his laboratory: a history of the Lawrence Berkeley Laboratory. Berkeley: University of California Press; 1989.

2. Miale Jr A. Nuclear medicine: reflections in time. J Florida Med Assoc. 1995;82:749-50.

3. Blower PJ. A nuclear chocolate box: the periodic table of nuclear medicine. Dalton Trans. 2015;44:4819-44.

4. Dilworth JR, Parrott SJ. The biomedical chemistry of technetium and rhenium. Chem Soc Rev. 1998;27:43-55.

5. Price EW, Orvig C. Matching chelators to radiometals for radiopharmaceuticals. Chem Soc Rev. 2014;43:260-90.

6. Vugts DJ, Visser GWM, van Dongen G. Zr-89-PET radiochemistry in the development and application of therapeutic monoclonal antibodies and other biologicals. Curr Top Med Chem. 2013;13:446-57.

7. Charoenphun P, Meszaros LK, Chuamsaamarkkee K, Sharif-Paghaleh E, Ballinger JR, Ferris TJ, Went MJ, Mullen GED, Blower PJ. Zr-89 Oxinate(4) for long-term in vivo cell tracking by positron emission tomography. Eur J Nucl Med Mol Imaging. 2015;42:278-87.

8. Hueting R. Radiocopper for the imaging of copper metabolism. J Labelled Comp Radiopharm. 2014;57:231-8. 
9. Fruhwirth GO, Diocou S, Blower PJ, Ng T, Mullen GED. A whole-body dual-modality radionuclide optical strategy for preclinical imaging of metastasis and heterogeneous treatment response in different microenvironments. J Nucl Med. 2014;55:686-94.

10. de Rosales RTM, Tavare R, Paul RL, Jauregui-Osoro M, Protti A, Glaria A, Varma G, Szanda I, Blower PJ. Synthesis of Cu-64(II)-Bis(dithiocarbamatebisphosphonate) and its conjugation with superparamagnetic iron oxide nanoparticles: in vivo evaluation as dual-modality PETMRI agent. Angew Chem Int Ed. 2011;50:5509-13. 


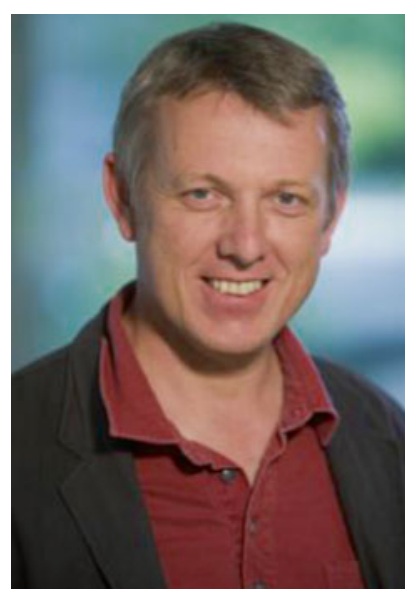

Philip J. Blower Since 2006 Phil Blower has been at King's College London as Chair in Imaging Chemistry in the Division of Imaging Sciences and Biomedical Engineering. As Head of the Imaging Chemistry and Biology Dept., he has built a large interdisciplinary research group with wide interests covering radiopharmaceutical chemistry and biology for PET, SPECT and radionuclide therapy, including a continuing focus on copper radionuclides (especially in hypoxia imaging) as well as technetium, rhenium, gallium, fluorine and more recently gallium and zirconium. $\mathrm{He}$ is PI or co-PI on current grants worth about $£ 25 \mathrm{~m}$, including a Cancer Research UK/EPSRC Cancer Imaging Centre, a Wellcome/EPSRC Medical Engineering Centre, and an EPSRC Doctoral Training Centre in Medical Imaging. He has published more than 150 peer-reviewed papers and supervised more than 28 successful PhD students. He has served on various peer review panels for international grant awarding bodies and journals and as Editor in Chief of Nuclear Medicine Communications. His path to this point followed a BA in Natural Sciences (Cambridge) and DPhil in Chemistry (Sussex), and postdoctoral experience in inorganic chemistry at Indiana University and Oxford University. His first academic post was a joint appointment at Kent and Canterbury Hospital (Radiopharmacy) and the University of Kent (Biosciences), where he combined the two roles to develop a number of new radiopharmaceuticals for imaging and therapy, including the earliest clinical evaluation of Re-186 and Re-188 targeted therapeutic radiopharmaceuticals and pioneering use of copper radionuclides for PET in Europe. 